\title{
BMJ Open Prevalence and correlates of overweight and obesity among adolescents in northeastern China: a cross-sectional study
}

\author{
Ruixin Duan, ${ }^{1,2}$ Changgui Kou, ${ }^{1}$ Jing Jie, ${ }^{2}$ Wei Bai, ${ }^{1}$ Xiaoxin Lan, ${ }^{2}$ Yuanyuan Li, ${ }^{1}$ \\ Xiao Yu, ${ }^{1}$ Bo Zhu, ${ }^{1}$ Haibo Yuan (i) ${ }^{2}$
}

To cite: Duan R, Kou C, Jie J, et al. Prevalence and correlates of overweight and obesity among adolescents in northeastern China: a crosssectional

study. BMJ Open

2020;10:e036820. doi:10.1136/

bmjopen-2020-036820

- Prepublication history for this paper is available online. To view these files, please visit the journal online (http://dx.doi org/10.1136/bmjopen-2020036820).

Received 07 January 2020 Revised 18 May 2020 Accepted 18 May 2020

D Check for updates

(C) Author(s) (or their employer(s)) 2020. Re-use permitted under CC BY-NC. No commercial re-use. See rights and permissions. Published by BMJ.

${ }^{1}$ Department of Epidemiology and Biostatistics, School of Public Health, Jilin University, Changchun, Jilin, China

${ }^{2}$ Pulmonary Division and Sleep Center, The First Hospital of Jilin University, Changchun, Jilin, China

Correspondence to

Dr Haibo Yuan;

hyuan@jlu.edu.cn

\section{ABSTRACT}

Objectives To estimate the prevalence of overweight/ obesity among adolescents and evaluate the associated factors in this group in Changchun City in northeastern China.

Methods A cross-sectional study of 1955 adolescents aged 11-18 years was conducted in Changchun City using stratified cluster sampling. Parents and caregivers of children completed the questionnaires as requested without objection. The questionnaire included demographic characteristics and anthropometric parameters. Univariate and multivariate logistic regression analyses were performed to analyse the relationship between overweight/ obesity and related factors.

Results In total, the prevalence of overweight was $12.7 \%$ (male 17.4\%; female 10.1\%) and of obesity was 4.9\% (male 8.8\%; female 3.1\%) in Changchun, Jilin Province. The prevalence of overweight and obesity was higher in boys than in girls $(p<0.001)$. Multivariate logistic regression showed that overweight and obesity were significantly associated with male sex $(\mathrm{OR}=1.91,95 \%$ $\mathrm{Cl} 1.48$ to 2.47), eating fresh fruits more than 2 days per week (OR=1.41, 95\% $\mathrm{Cl} 1.09$ to 1.84 ) and eating quickly $(\mathrm{OR}=1.37,95 \% \mathrm{Cl} 1.06$ to 1.78$)$. Students who were not picky ( $\mathrm{OR}=0.69,95 \% \mathrm{Cl} 0.53$ to 0.90 ) were less likely to be overweight, and adolescents whose father was overweight or obese $(\mathrm{OR}=0.67,95 \% \mathrm{Cl} 0.52$ to 0.86$)$ or whose mother was overweight or obese $(\mathrm{OR}=0.72,95 \% \mathrm{Cl}$ 0.52 to 0.99 ) were less likely to be overweight.

Conclusion The prevalence of overweight and obesity among adolescents in Changchun has been high in recent years, and the prevalence was higher among boys than among girls. Sex, dietary habits (weekly frequency of fruit consumption, picky eating and slowness in eating) and parental weight were important factors for overweight and obesity in adolescents. Further research should be conducted on the health of adolescents in China, and further intervention measures should be implemented to reduce the prevalence of overweight/obesity.

\section{INTRODUCTION}

The prevalence of obesity has increased dramatically among children, adolescents and adults worldwide in recent decades. ${ }^{1}$ Overall, the global proportion of adolescents with
Strengths and limitations of this study

- In this cross-sectional study, participants were randomly selected from rural and urban areas by stratified cluster sampling

- Weight category was defined using age-specific and sex-specific body mass index cut-off points specifically developed for the Chinese adolescent population.

- The influence of confounding factors on the results was effectively controlled by the multivariate logistic regression method.

- Missing data from childhood measurements were handled with a mean imputation technique.

- The content of the questionnaire was mostly recalled by the parents or guardians and there might be information bias in this survey.

obesity has increased significantly from just $4 \%$ in 1975 to just over $18 \%$ in $2016 .{ }^{2}$ There is compelling evidence revealing a significantly higher proportion of overweight or obese adolescents in recent years, which has reached alarming levels. Recently, scholars have conducted many studies on overweight and obesity. Overweight and obesity are predisposing factors for many chronic diseases, such as type 2 diabetes, cardiovascular diseases, respiratory diseases, musculoskeletal disorders and various types of cancer. ${ }^{3}$ Rong et $a t^{t}$ found an association of adolescent obesity with non-alcoholic fatty liver disease (NAFLD) and revealed that the incidence of NAFLD increased with increasing body weight. Lisan $e t a \tilde{l}$ compared patients with obesity and severe obstructive sleep apnoea (OSA) with and without prescription of positive airway pressure (PAP) therapy and found that participants with PAP prescriptions had a higher body mass index (BMI) than participants not prescribed PAP. It has been estimated that overweight and obesity are the 
fifth leading cause of death worldwide, accounting for nearly 3.4 million deaths annually. ${ }^{6}$ In addition, obesity is considered a risk factor for the development of chronic kidney disease. ${ }^{7}$ In this context, the American Medical Association classified obesity as a disease to get physicians to pay more attention to the condition. ${ }^{8}$

In China, the largest developing country, nearly onethird of adolescents were overweight or obese in 2016, and the prevalence rate of obesity increased from $0.10 \%$ in 1976 to $8.50 \%$ in 2016 . Sun et at found that the prevalence of obesity and of overweight and obesity combined was $8.1 \%$ and $19.2 \%$, respectively, among children and adolescents aged $7-18$. Zhang et $a l^{10}$ reported that the prevalence rates of overweight and obesity among primary school children were $15.2 \%$ and $11.7 \%$, respectively, in Jiangsu Province. Therefore, it is of key importance to understand the risk factors for overweight and obesity to prevent adolescents from developing the disease.

We investigated the physical condition of adolescents aged 11-18 years from six middle schools in Changchun, which is the capital of Jilin Province. The aims of the current study were to determine the prevalence of overweight and obesity and to analyse various associated factors among adolescents with overweight and obesity in Changchun, Jilin.

\section{METHODS}

\section{Subjects}

A cross-sectional survey was conducted in Changchun City, the capital of Jilin Province in northeastern China. The study sample comprised middle and high school students from six middle schools (three in urban areas and three in rural areas), selected randomly using stratified cluster sampling. Overall, 1955 students aged 11-18 years were included in this cross-sectional survey; subjects with overweight/obesity due to known metabolic and endocrine diseases were excluded. Students were also excluded if they had mental or physical impairments severe enough to cause abnormal behaviours, including congenital disease, intellectual disability and psychiatric disorder. ${ }^{11}$ We used the Strengthening the Reporting of Observational Studies in Epidemiology checklist in this study.

\section{Data collection}

The study was carried out by the First Hospital of Jilin University in April 2016. The investigation received informed consent from students and parents. The project was named 'Effect and mechanism of weight loss on upper airway collapsibility in obese patients with Obstructive Sleep Apnea Syndrome (OSAS)' and studied the associations of overweight, obesity and related factors with sleeprelated breathing disorders and snoring in adolescents. In this database, we focused on the relevant indicators of overweight and obesity in adolescents and analysed the risk factors for obesity in adolescents. The interviewers from the First Hospital of Jilin University helped the parents or guardians to complete the questionnaire and provided the data. The questionnaire included demographic characteristics (age, sex, area, dietary habits, sleep, exercise, highest parental education, birth history, BMI classification, paternal weight and maternal weight), anthropometric parameters (weight, height) and the Paediatric Sleep Questionnaire-Sleep-Related Breathing Disorder (PSQ-SRBD). Data about sleep duration and dietary habits (frequency of fresh fruits consumption, frequency of dessert consumption, frequency of breakfast consumption, frequency of fast food consumption, slowness in eating, picky eating) were selected from the PSQ-SRBD scale according to various reports ${ }^{12-14}$ about adolescent obesity.

\section{Key variables}

BMI is used here as an indicator of overweight and obesity in adolescents and adults. Weight category was defined using age-specific and sex-specific BMI cut-off points specifically developed for the Chinese adolescent population. ${ }^{15}$ We used the 85 th and 95 th percentiles to define overweight and obesity in adolescents. Therefore, BMI values of 24 and 28 were used as cut-off points for overweight and obesity, both for boys and girls aged 18 years, which were consistent with Chinese adults. In our study, parental overweight was divided into two groups: normal (BMI <24) and overweight or obese (BMI 224). ${ }^{1416}$ Parents and caregivers provided information on adolescents' weight (to the nearest $1 \mathrm{~kg}$ ) and height (to the nearest $1 \mathrm{~cm}$ ). Overall, children were classified by age into three groups ( $<13$ years, $13-15$ years, $>15$ years), by region into two groups (urban, rural) and by sex into two groups (male, female). Participants who slept less than 8 hours over 3 days a week were classified as 'sleep $<8$ hours', and those who slept more than 10 hours over 3 days a week were defined as 'sleep $>10$ hours' ${ }^{17}$ Birth history was divided into three groups: preterm birth (infants born alive before 37 weeks of pregnancy), full-term birth (infants born alive after 37 completed weeks to less than 42 completed weeks) and post-term birth (infants born alive at 42 completed weeks or after).$^{18}$ Parental educational level was divided into four groups: primary school or lower (including those who had never attended school and those with elementary schooling only), junior high school, senior high school (including those with 3 years of secondary vocational schooling) and university or above. ${ }^{17}$ According to the content of the questionnaire, we classified participants' eating habits. According to the Food Guide Pagoda, ${ }^{19}$ fruit intake should be $200-350 \mathrm{~g} /$ day and sugar intake should be no more than $50 \mathrm{~g} /$ day, so we used eating 'fresh fruits more than two days per week $(350 \mathrm{~g} / \mathrm{d})$ ', 'dessert more than two days per week', 'breakfast more than two days per week' and 'fast food more than two days per week' as cut-offs. Participants who were classified as 'picky eating' were defined as adolescents who had selectivity for a particular kind of food. ${ }^{20}$ 'Slowness in eating' was defined as adolescents with higher masticatory performance and who ate slowly. ${ }^{21}$ 
Table 1 Prevalence of overweight and obesity according to demographic characteristics

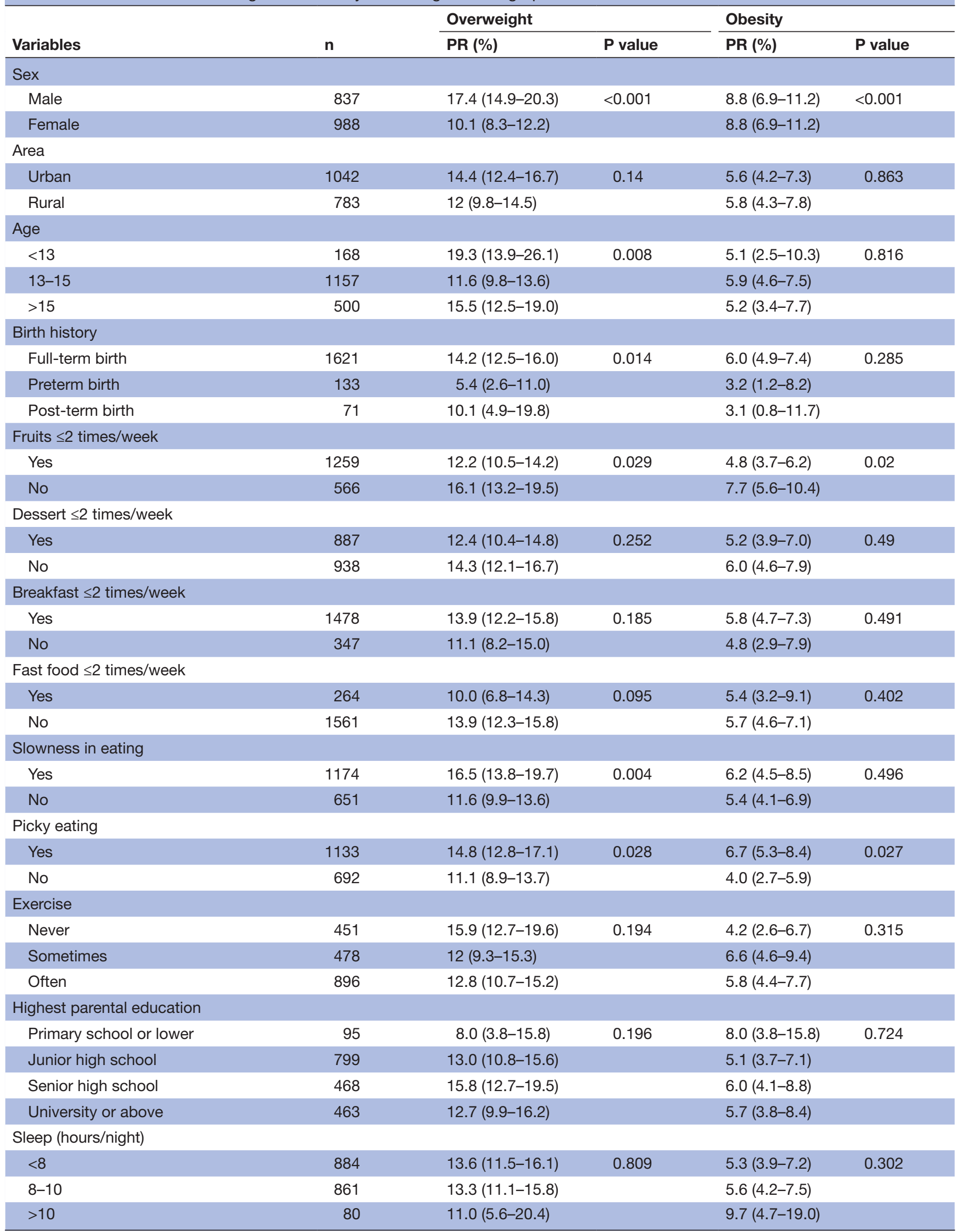


Table 1 Continued

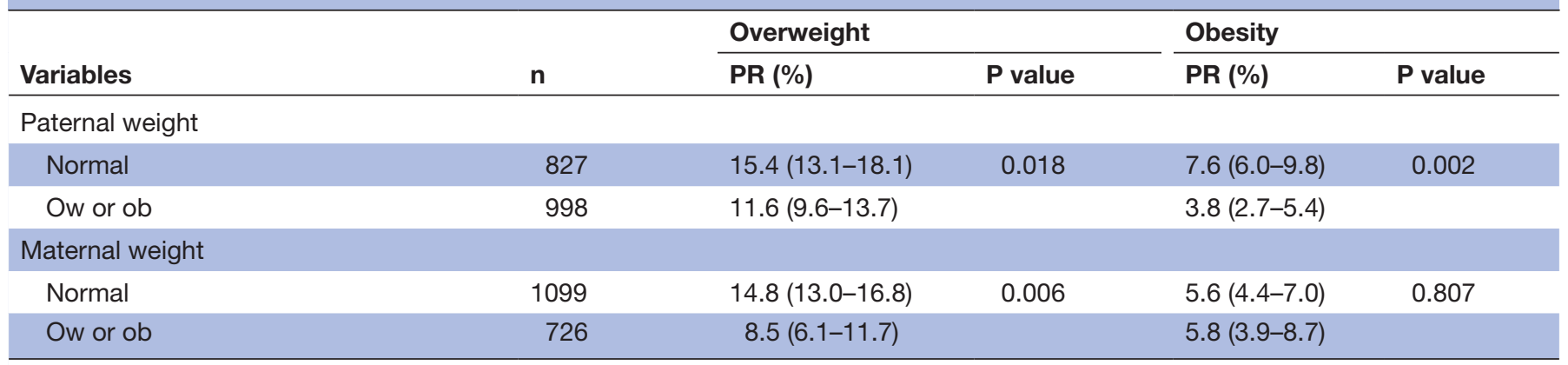

Ob, obese; Ow, overweight; PR, prevalence rate.

Groups were formed according to the number of exercise days (aerobic, strength training or both for at least 30 min a day), including never (participate in sports $\leq 1$ day per week), sometimes (participate in sports 2-3 days per week) and often (participate in sports $\geq 4$ days per week). ${ }^{22} 23$

\section{Statistical analysis}

Data input was performed using EpiData V.3.1, and statistical analysis was performed using SPSS V.24.0. Frequency distributions are used to characterise subjects, and percentage data are used to report prevalence. The relationship between each factor and the adolescents' weight status was reflected by $\chi^{2}$ tests and univariate and multivariate logistic regression. In univariate analysis, when $\mathrm{p}<0.10$, significant correlation factors were included in a forward stepwise multivariate logistic regression to exclude confounding factors. In all analyses, a two-tailed $p$ value $<0.05$ was considered statistically significant. Since the database was manually collated, some variables in the database had missing values, which resulted in waste and bias of data resources. The missing value was numeric, and the data were approximately normally distributed. The mean interpolation method was adopted in this study. Therefore, we used the 'replace missing value' function in SPSS V.24.0 and selected the "mean of nearby points' method to interpolate the missing values.

\section{Patient and public involvement}

The interviewers from the First Hospital of Jilin University helped parents or guardians complete the questionnaire and provided the data. The adolescents were not involved in the design, recruitment or conduct of the study.

\section{RESULTS}

On the basis of the inclusion and exclusion criteria, we chose 1955 adolescents from Changchun, and of these adolescents 1825 were finally analysed in this study. Participants with missing BMI values were excluded from the study. Since the survey was already completed, we were unable to verify the source of data errors, so we deleted data with missing BMI values. According to the analysis of the frequency distribution, we found that there were
837 boys and 988 girls included; the median age of the students was 15.30 years, ranging from 11 to 18 years. Of these subjects, $42.9 \%$ were from rural regions and $57.1 \%$ were from urban regions, and most of the subjects were Han Chinese, accounting for $98.2 \%$, with only a few participants with minority ethnicities.

According to the worldwide BMI classification, the overall prevalence of overweight was $12.7 \%$ (male 17.4\%; female $10.1 \%$ ) and the prevalence of obesity was $4.9 \%$ (male 8.8\%; female 3.1\%) in Changchun City, Jilin Province (table 1). Overweight and obesity rates were both higher in boys than in girls $(\mathrm{p}<0.001)$. A higher prevalence of overweight was found in subjects whose ages ranged from 11 to 12 years, and the prevalence of obesity was higher in the 13-15 years age group $(p=0.008)$. Children from urban areas showed a significantly higher proportion of overweight. Full-term birth subjects had a higher prevalence of overweight than others $(p=0.014)$. In addition, students who ate fruits more than twice a week $(\mathrm{p}=0.029)$, ate slowly $(\mathrm{p}=0.004)$ and were picky $(\mathrm{p}=0.028)$ had a higher prevalence of overweight in the study. Paternal weight $(\mathrm{p}=0.018)$ and maternal weight $(p=0.006)$ also had an effect on children's weight.

To facilitate regression analysis, we divided the participants into two groups: underweight/normal weight and overweight/obese. Table 2 shows the univariate analysis of correlates of overweight and obesity in adolescents. As impressively demonstrated in this table, the following factors all showed significant differences between the two groups: sex, age, birth history, frequency of eating fruits, eating habits (slowness in eating, picky eating) and parental weights $(\mathrm{p}<0.05)$. According to the results, we added all these significant factors to a forward stepwise multivariate logistic regression model.

Table 3 shows the results of logistic regression models comparing the prevalence of the potential risk factors: sex, age, birth history, frequency of eating fruits, dietary habits (slowness in eating, picky eating) and parental weight. In this forward stepwise multivariate logistic regression model, boys were more likely to be overweight and obese than girls ( $\mathrm{OR}=1.91,95 \%$ CI 1.48 to 2.50$)$. Students aged $13-15$ years $(\mathrm{OR}=0.63,95 \%$ CI 0.42 to 0.96$)$ were less likely to be overweight than those aged 11-12 years. Compared 
Table 2 Univariate analysis of correlates of overweight and obesity in adolescents in Changchun

\begin{tabular}{|c|c|c|c|}
\hline Variables & $P$ value & OR & $95 \% \mathrm{Cl}$ \\
\hline \multicolumn{4}{|l|}{ Sex } \\
\hline Female & $<0.001$ & 1 & \\
\hline Male & & 2.13 & 1.66 to 2.72 \\
\hline \multicolumn{4}{|l|}{ Area } \\
\hline Urban & 0.256 & 1 & \\
\hline Rural & & 1.15 & 0.90 to 1.47 \\
\hline \multicolumn{4}{|l|}{ Age } \\
\hline$<13$ & 0.070 & 1 & \\
\hline $13-15$ & 0.041 & 0.67 & 0.45 to 0.98 \\
\hline$>15$ & 0.339 & 0.81 & 0.53 to 1.24 \\
\hline \multicolumn{4}{|l|}{ Birth history } \\
\hline Full-term birth & 0.008 & 1 & \\
\hline Preterm birth & 0.004 & 0.40 & 0.21 to 0.74 \\
\hline Post-term birth & 0.209 & 0.63 & 0.31 to 1.29 \\
\hline \multicolumn{4}{|c|}{ Fresh fruits $\leq 2$ times/week } \\
\hline Yes & 0.003 & 1 & \\
\hline No & & 1.46 & 1.13 to 1.87 \\
\hline
\end{tabular}

Dessert $\leq 2$ times/week

$\begin{array}{llll}\text { Yes } & 1.197 & 1 & \\ \text { No } & & 1.17 & 0.92 \text { to } 1.49 \\ \begin{array}{l}\text { Breakfast } \leq 2 \text { times/week } \\ \text { Yes }\end{array} & 0.15 & 1 & \\ \quad \text { No } & & 0.79 & 0.57 \text { to } 1.09 \\ \begin{array}{l}\text { Fast food } \leq 2 \text { times/week } \\ \text { Yes }\end{array} & 0.135 & 1 & \\ \quad \text { No } & & 1.32 & 0.92 \text { to } 1.91 \\ \begin{array}{l}\text { Slowness in eating } \\ \text { Yes }\end{array} & 0.007 & 1 & \\ \text { No } & & 0.71 & 0.56 \text { to } 0.91\end{array}$

Picky eating

\begin{tabular}{llll}
\hline Yes & 0.004 & 1 & \\
\hline No & & 0.69 & 0.53 to 0.88 \\
\hline $\begin{array}{l}\text { Exercise } \\
\text { Never }\end{array}$ & 0.74 & 1 & \\
\hline Sometimes & 0.502 & 0.89 & 0.64 to 1.25 \\
\hline $\begin{array}{l}\text { Often } \\
\text { Highest parental education }\end{array}$ & 0.484 & 0.90 & 0.67 to 1.21 \\
\hline $\begin{array}{l}\text { Primary school or lower } \\
\text { Junior high school }\end{array}$ & 0.411 & 1 & \\
\hline $\begin{array}{l}\text { Senior high school } \\
\text { University or above }\end{array}$ & 0.594 & 1.18 & 0.65 to 2.14 \\
\hline Sleep (hours/night) & 0.58 & 1.45 & 0.79 to 2.68 \\
\hline$<8$ & & & 0.64 to 2.21 \\
\hline 8-10 & 0.964 & 1 & \\
\hline$>10$ & 0.952 & 0.99 & 0.78 to 1.27 \\
\hline
\end{tabular}

Continued
Table 2 Continued

\begin{tabular}{llll}
\hline Variables & P value & OR & $\mathbf{9 5 \%} \mathbf{C l}$ \\
\hline $\begin{array}{l}\text { Paternal weight } \\
\text { Normal }\end{array}$ & 0.001 & 1 & \\
Ow or ob & & 0.64 & 0.51 to 0.83 \\
$\begin{array}{l}\text { Maternal weight } \\
\text { Normal }\end{array}$ & 0.011 & 1 & \\
Ow or ob & & 0.67 & 0.49 to 0.91 \\
\hline
\end{tabular}

Ob, obese; Ow, overweight.

with full-term birth, preterm birth $(\mathrm{OR}=0.45,95 \%$ CI 0.24 to 0.85 ) was associated with normal weight. Participants who ate fruits more than twice a week $(\mathrm{OR}=1.41,95 \% \mathrm{CI}$ 1.09 to 1.84 ) were more likely to be overweight or obese. Moreover, the prevalence of overweight was higher in students who ate quickly (OR=1.37, 95\% CI 1.06 to 1.78 ) than those who ate slowly. Compared with picky eaters, students who were not picky $(\mathrm{OR}=0.69,95 \%$ CI 0.53 to $0.90)$ were less likely to be overweight.

\section{DISCUSSION}

To describe the epidemiology of overweight and obesity in Changchun City and analyse the influencing factors in adolescents, we conducted this survey of middle school students aged 11-18 years from urban and rural areas. We found that sex, dietary habits and parental weight had a significant impact on children's weight.

Based on the data, we found that the prevalence of overweight was $12.7 \%$ (male $17.4 \%$; female $10.1 \%$ ) and of obesity was $4.9 \%$ (male $8.8 \%$; female $3.1 \%$ ) among adolescents in Changchun City, Jilin Province. However, in recent studies, the overall prevalence of obesity in school-aged children in Xi'an was $4.11 \%$, and the rate of overweight was $6.6 \%$ among Nanjing adolescents; these rates were both lower than the corresponding rates in Changchun. This difference may be caused by sample size, sex and age of the studied population. ${ }^{24}{ }^{25}$ In addition, demographic distribution and environmental factors are probable factors. ${ }^{26}$ The economy in northeastern China is less developed than in the east and south of China to some extent. ${ }^{27}$ Rates of overweight and obesity in rural areas were also higher in the north than in the south. ${ }^{28}$ Depending on the season, people in the north might eat high-energy foods to combat the cold, which is referred to 'energy balance related behaviors'. ${ }^{29}{ }^{30}$ In our data, boys were more often obese than girls, in general, which was in agreement with previous Chinese reports. ${ }^{30-32}$ A Swedish report ${ }^{33}$ predicted that there was an alarming increase in the prevalence of overweight and obesity among adolescent boys, which was consistent with our finding. On the one hand, in traditional Chinese culture, the preference for boys may be the reason for the differences in diet, and the elderly believe that fat boys are more powerful than thin boys. On the other hand, well-groomed and fit girls 
Table 3 Multivariate regression analysis of correlates of overweight and obesity in adolescents in Changchun

\begin{tabular}{|c|c|c|c|c|c|}
\hline Variables & $P$ value & $\beta$ & SE & OR & $95 \% \mathrm{Cl}$ \\
\hline \multicolumn{6}{|l|}{ Sex } \\
\hline Female & & & & 1 & \\
\hline \multicolumn{6}{|l|}{ Age } \\
\hline$<13$ & & & & 1 & \\
\hline$>15$ & 0.121 & -0.35 & 0.23 & 0.70 & 0.45 to 1.10 \\
\hline \multicolumn{6}{|l|}{ Birth history } \\
\hline Full-term birth & & & & 1 & \\
\hline Preterm birth & 0.014 & -0.80 & 0.33 & 0.45 & 0.24 to 0.85 \\
\hline Post-term birth & 0.337 & -0.36 & 0.37 & 0.70 & 0.34 to 1.45 \\
\hline \multicolumn{6}{|l|}{ Slowness in eating } \\
\hline Yes & & & & 1 & \\
\hline No & 0.016 & 0.32 & 0.13 & 1.37 & 1.06 to 1.78 \\
\hline \multicolumn{6}{|l|}{ Picky eating } \\
\hline Yes & & & & 1 & \\
\hline No & 0.007 & -0.37 & 0.14 & 0.69 & 0.53 to 0.90 \\
\hline \multicolumn{6}{|l|}{ Paternal weight } \\
\hline Normal & & & & 1 & \\
\hline Ow or ob & 0.002 & -0.41 & 0.13 & 0.67 & 0.51 to 0.83 \\
\hline
\end{tabular}

Ob, obese; Ow, overweight.

are more favoured by Chinese society. ${ }^{34-36}$ Girls also tend to be more concerned about their weight than boys.

We also found that adolescents who were picky, ate more fruits in general and ate quickly were more likely to be overweight or obese according to our survey. In recent reports, ${ }^{37}$ a greater fruit intake was a protective factor against overweight, which was opposite to our results. Fructose, which is ubiquitously found in fruit and sugarsweetened beverages, is one of the factors contributing to the rising rates of obesity. ${ }^{39}{ }^{40}$ High intake of fructose may reduce the abundance of the bacterial species Eubacterium eligens, reduce metabolism of monosaccharide and lose the ability to consume large amounts of fat. ${ }^{41}$ The fructose intake threshold for adolescents is currently averaged at $75 \mathrm{~g} /$ day. If teenagers get too much fructose without consuming glycogen in time, fructose will be converted into fats at a higher rate. ${ }^{42}{ }^{43}$ Based on the results of our study, it was reasonable to speculate that the children were already full in addition to the excessive intake of fruits with high sugar content. Moreover, the heavy study task in China makes children fail to consume extra energy through exercise, leading to the possibility of being overweight. For obese children, parents believe they can control their weight by increasing fruit intake. This may also have contributed to the fact that the children in our cross-sectional study who ate more fruits were more likely to be overweight. However, given our inconsistent results with previous findings, ${ }^{3738}$ whether the reason is due to different classifications needs further research.

According to a recent study, ${ }^{44}$ food preference was an independent risk factor for overweight among children. It is known that children who had selectivity for a particular kind of food would prefer more fast food, snacks and sugary beverage ${ }^{45}$ and fewer fruits and vegetables. ${ }^{46}$ However, the frequency of dessert and fast food consumption had no significant effect in our study, perhaps because the data were provided by parents or guardians who provided an inaccurate account of how often their children ate sweets and fast food. Currently, several studies have considered that food intake is a primary factor that determines body weight. ${ }^{47-49} \mathrm{Li}$ et $a l^{22}$ concluded that excessive intake of cooking oil might 
be one of the risk factors for overweight. According to a previous study in Tianjin, ${ }^{47}$ overweight students preferred significantly more sweet food and take-out food than their counterparts with normal weight. The result might be influenced by many elements, such as peer influence, food price, convenience, online influence and so on, based on a recent report. ${ }^{50}$ To reduce the prevalence of overweight and obesity, a series of interventions have been implemented, such as controlling television time and increasing sports time.

In our research, we found that if fathers and mothers were overweight, adolescents were less likely to be overweight, which was inconsistent with previous conclusions. ${ }^{51-53}$ Studies $^{54}{ }^{55}$ have found that higher BMI in fathers increased the risk of overweight/obesity among boys and girls. However, these findings were not consistent across studies. In a previous study, the researchers found that the relationship between parents' and children's BMI did not exist when longitudinal analyses of changes in BMI over 4 years were performed. ${ }^{56}$ This may explain why a short period of periodic surveys alone does not fully demonstrate a parent-child link to obesity, and we still need long-term research to further explore the relationship between the two factors. Berge $e t a b^{7}$ found that overweight or obese parents were more likely to adopt a strict dietary restriction to prevent adolescent obesity. Moreover, children's growing environment and living habits will also affect their own obesity levels, which will have an impact on our results. ${ }^{50}$ Further prospective studies that assess both energy expenditure and energy intake in children are more likely to clarify this concept.

Some potential limitations exist in this cross-sectional study. The content of the questionnaire was mostly recalled by the parents or guardians and there might be information bias in this survey. In addition, we set the classification standard of eating fruit frequency as 'eating fruit 2 days a week' combined with the questionnaire data recalled by the parents or guardians, which may not be appropriate. Further studies considering different classifications and a quantitative measurement are required.

\section{CONCLUSIONS}

In summary, in this cross-sectional study, we found that the prevalence of overweight and obesity among adolescents in Changchun, Jilin Province was high. Sex, age, birth history, dietary habits and parental weight were important factors for overweight and obesity in adolescents. Therefore, reasonable lifestyle and effective weight control are necessary to prevent overweight and obesity in adolescents. There are still several limitations to this study, and we need to obtain more accurate information and perform more specific analysis. Further research should be conducted on the health of adolescents in China, and further intervention measures should be implemented to reduce the prevalence of overweight and obesity.
Acknowledgements The authors would like to thank all those who helped with the investigation and the participants.

Contributors RD, CK and HY conceived the study and participated in the design of the study. HY, JJ and XL collected the data. RD carried out the measurements, analysed the data and drafted the manuscript. XY and BZ participated in the coordination of the study and interpreted the data. WB and YL revised the manuscript. All authors have approved the final article.

Funding This study was supported by the National Key Research and Development Program (2016YFC1300100) and the National Natural Science Foundation of China (grant number: 81970081, 81300062).

Competing interests None declared.

Patient consent for publication Not required.

Ethics approval The investigation was conducted by the First Hospital of Jilin University in April 2016. The study was approved by the ethics committee of the First Hospital of Jilin University (reference number: 2013-031).

Provenance and peer review Not commissioned; externally peer reviewed.

Data availability statement Data are available in a public, open access repository. Extra data can be accessed via the Dryad Data Repository at http://datadryad. org/ with the doi:10.5061/dryad.g1jwstqnw. Data referenced in this study are available in the project titled 'Effect and mechanism of weight loss on upper airway collapsibility in obese patients with OSAS'. We selected a portion of the data from the database, including body measurements of adolescents from six middle schools in Changchun City. The data that support the findings of this study are available on request from the corresponding author ( $\mathrm{HY})$. The data are not publicly available because they contain information that could compromise research participants' privacy or consent.

Open access This is an open access article distributed in accordance with the Creative Commons Attribution Non Commercial (CC BY-NC 4.0) license, which permits others to distribute, remix, adapt, build upon this work non-commercially, and license their derivative works on different terms, provided the original work is properly cited, appropriate credit is given, any changes made indicated, and the use is non-commercial. See: http://creativecommons.org/licenses/by-nc/4.0/.

ORCID iD

Haibo Yuan http://orcid.org/0000-0003-4178-1328

\section{REFERENCES}

1 Abarca-Gómez L, Abdeen ZA, Hamid ZA, et al. Worldwide trends in body-mass index, underweight, overweight, and obesity from 1975 to 2016: a pooled analysis of 2416 population-based measurement studies in 128.9 million children, adolescents, and adults. The Lancet 2017;390:2627-42.

2 World Health Organization. Global health observatory data repository, 2017. Available: http://apps.who.int/gho/data/view.main. BMIPLUS2C10-19v?lang=en [Accessed 29 Sep 2017].

3 Jiang Y, Wang J, Wu S, et al. Association between Take-Out food consumption and obesity among Chinese university students: a cross-sectional study. Int J Environ Res Public Health 2019;16:1071.

4 Rong Y, Chun-Yan N, Hong-Xin Z, et al. Association of adolescent obesity with nonalcoholic fatty liver disease and related risk factors in Xi 'an, China. Ann Hepatol 2018;17:85-91.

5 Lisan Q, Van Sloten T, Marques Vidal P, et al. Association of positive airway pressure prescription with mortality in patients with obesity and severe obstructive sleep apnea: the sleep heart health study. JAMA Otolaryngol Head Neck Surg 2019;145:509.

6 Lai SH, Tsai YW, Chen YC, et al. Obesity, hyperhomocysteinaemia and risk of chronic kidney disease: a population-based study. Family Practice 2017;35.

7 Sabanayagam C, Wong TY, Liao J, et al. Body mass index and preclinical kidney disease in Indian adults aged 40 years and above without chronic kidney disease. Clin Exp Nephrol 2014;18:919-24.

8 Addo PNO, Nyarko KM, Sackey SO, et al. Prevalence of obesity and overweight and associated factors among financial institution workers in Accra Metropolis, Ghana: a cross sectional study. BMC Res Notes 2015;8:599.

9 Sun H, Ma Y, Han D, et al. Prevalence and trends in obesity among China's children and adolescents, 1985-2010. PLoS One 2014;9:e105469.

10 Zhang X, Zhang F, Yang J, et al. Prevalence of overweight and obesity among primary school-aged children in Jiangsu Province, China, 2014-2017. PLoS One 2018;13:e0202681. 
11 Ma Y, Peng L, Kou C, et al. Associations of overweight, obesity and related factors with sleep-related breathing disorders and snoring in adolescents: a cross-sectional survey. Int J Environ Res Public Health 2017:14:194

12 Rangan A, Zheng M, Olsen NJ, et al. Shorter sleep duration is associated with higher energy intake and an increase in BMI $z$-score in young children predisposed to overweight. Int J Obes 2018;42:59-64

13 Dello Russo M, Ahrens W, De Henauw S, et al. The impact of adding sugars to milk and fruit on adiposity and diet quality in children: a cross-sectional and longitudinal analysis of the identification and prevention of dietary- and Lifestyle-Induced health effects in children and infants (IDEFICS) study. Nutrients 2018;10:1350.

14 Wang $\mathrm{H}$, Zhai F. Programme and policy options for preventing obesity in China. Obesity Reviews 2013;14:134-40.

15 Group of China Obesity Task Force. [Body mass index reference norm for screening overweight and obesity in Chinese children and adolescents]. Zhonghua Liu Xing Bing Xue Za Zhi 2004;25:97-102.

16 Zhou L, Zeng Q, Jin S, et al. The impact of changes in dietary knowledge on adult overweight and obesity in China. PLoS One 2017; 12:e0179551.

17 Wang R, Zhang P, Gao C, et al. Prevalence of overweight and obesity and some associated factors among adult residents of northeast China: a cross-sectional study. BMJ Open 2016;6:e010828.

18 Slack E, Best KE, Rankin J, et al. Maternal obesity classes, preterm and post-term birth: a retrospective analysis of 479,864 births in England. BMC Pregnancy Childbirth 2019;19:434.

19 Wang S-S, Lay S, Yu H-N, et al. Dietary guidelines for Chinese residents (2016): comments and comparisons. J Zhejiang Univ Sci B 2016;17:649-56.

20 Antoniou EE, Roefs A, Kremers SPJ, et al. Picky eating and child weight status development: a longitudinal study. J Hum Nutr Diet 2016;29:298-307.

21 Oberle MM, Romero Willson S, Gross AC, et al. Relationships among child eating behaviors and household food insecurity in youth with obesity. Child Obes 2019;15:298-305.

22 Li Y, Zhai F, Yang X, et al. Determinants of childhood overweight and obesity in China. Br J Nutr 2007;97:210-5.

23 Kelley GA, Kelley KS. Exercise and BMI z-score in overweight and obese children and adolescents: protocol for a systematic review and network meta-analysis of randomised trials. BMJ Open 2016;6:e011258

$24 \mathrm{Xu} \mathrm{F}$, Li J, Ware RS, et al. Associations of television viewing time with excess body weight among urban and rural high-school students in regional mainland China. Public Health Nutr 2008;11:891-6.

25 Yi X, Yin C, Chang M, et al. Prevalence and risk factors of obesity among school-aged children in Xi'an, China. Eur J Pediatr 2012;171:389-94.

26 Hu L, Huang X, You C, et al. Prevalence of overweight, obesity, abdominal obesity and obesity-related risk factors in southern China. PLoS One 2017; 12:e0183934.

27 Li P, Jiang R, Li L, et al. Prevalence and risk factors of metabolic syndrome in school adolescents of northeast China. $J$ Pediatr Endocrinol Metab 2014;27:525-32.

28 Reynolds K, Gu D, Whelton PK, et al. Prevalence and risk factors of overweight and obesity in China. Obesity 2007;15:10-18.

29 Zhuo Q, Wang Z, Piao J, et al. Geographic variation in the prevalence of overweight and economic status in Chinese adults. $\mathrm{Br} \mathrm{J}$ Nutr 2009;102:413-8.

30 Jia P, Xue H, Zhang J, et al. Time trend and demographic and geographic disparities in childhood obesity prevalence in ChinaEvidence from twenty years of longitudinal data. Int $J$ Environ Res Public Health 2017;14:369.

31 Jia P, Li M, Xue H, et al. School environment and policies, child eating behavior and overweight/obesity in urban China: the childhood obesity study in China megacities. Int $J$ Obes 2017:41:813-9.

32 Zhang Y, Zhao J, Chu Z, et al. Increasing prevalence of childhood overweight and obesity in a coastal province in China. Pediatr Obes 2016;11:e22-6.

33 Eriksson M, Lingfors $\mathrm{H}$, Golsäter $\mathrm{M}$. Trends in prevalence of thinness, overweight and obesity among Swedish children and adolescents between 2004 and 2015. Acta Paediatr 2018;107:1818-25.
34 Li J, Lei J, Wen S, et al. Sex disparity and perception of obesity/ overweight by parents and grandparents. Paediatr Child Health 2014;19:e113-6.

35 Zhang J, Wang $\mathrm{H}$, Wang $\mathrm{Z}$, et al. Prevalence and stabilizing trends in overweight and obesity among children and adolescents in China, 2011-2015. BMC Public Health 2018;18:571.

36 Zhai L, Dong Y, Bai Y, et al. Trends in obesity, overweight, and malnutrition among children and adolescents in Shenyang, China in 2010 and 2014: a multiple cross-sectional study. BMC Public Health 2017;17:151.

37 You J, Choo J. Adolescent overweight and obesity: links to socioeconomic status and fruit and vegetable intakes. Int $J$ Environ Res Public Health 2016;13:307.

38 Tohill BC, Seymour J, Serdula M, et al. What epidemiologic studies tell us about the relationship between fruit and vegetable consumption and body weight. Nutr Rev 2004;62:365-74.

$39 \mathrm{Qi}$ X, Tester RF, Fructose TRF. Fructose, galactose and glucose - In health and disease. Clin Nutr ESPEN 2019;33:18-28.

40 Choo VL, Viguiliouk E, Blanco Mejia S, et al. Food sources of fructose-containing sugars and glycaemic control: systematic review and meta-analysis of controlled intervention studies. BMJ 2018;363:k4644.

41 Jones RB, Alderete TL, Kim JS, et al. High intake of dietary fructose in overweight/obese teenagers associated with depletion of Eubacterium and Streptococcus in gut microbiome. Gut Microbes 2019;10:712-9.

42 Lustig RH. Fructose: it's "alcohol without the buzz". Adv Nutr 2013:4:226-35

43 Aller EEJG, Abete I, Astrup A, et al. Starches, sugars and obesity. Nutrients 2011;3:341-69.

44 Xiong L-hua, Wang C-ling, Chen Z-qiu, et al. [Study on food preference and dietary behavior to overweight/obesity in school children and adolescents in Guangzhou: a case-control study]. Zhonghua Liu Xing Bing Xue Za Zhi 2008;29:965-9.

45 Qiu C, Hou M. Association between food preferences, eating behaviors and socio-demographic factors, physical activity among children and adolescents: a cross-sectional study. Nutrients 2020;12:640.

46 Ferreira RJ, Marques-Vidal PM. Prevalence and determinants of obesity in children in public schools of Sintra, Portugal. Obesity 2008;16:497-500.

47 Andegiorgish AK, Wang J, Zhang X, et al. Prevalence of overweight, obesity, and associated risk factors among school children and adolescents in Tianjin, China. Eur J Pediatr 2012;171:697-703.

48 Liu J, Hay J, Faught BE, et al. Family eating and activity habits, die quality and pre-adolescent overweight and obesity. Public Health 2012:126:532-4.

49 An R. Diet quality and physical activity in relation to childhood obesity. Int J Adolesc Med Health 2017;29

50 Watts AW, Lovato CY, Barr SI, et al. A qualitative study exploring how school and community environments shape the food choices of adolescents with overweight/obesity. Appetite 2015;95:360-7.

51 Næss M, Holmen TL, Langaas M, et al. Intergenerational transmission of overweight and obesity from parents to their adolescent offspring - The HUNT study. PLoS One 2016;11:e0166585.

52 Tu AW, Watts AW, Masse LC. Parent-Adolescent patterns of physical activity, sedentary behaviors and sleep among a sample of overweight and obese adolescents. J Phys Act Health 2015;12:1469-76.

53 Brennan L, Walkley J, Wilks R. Parent- and adolescent-reported barriers to participation in an adolescent overweight and obesity intervention. Obesity 2012;20:1319-24.

54 Jiang $\mathrm{M}-\mathrm{H}$, Yang $\mathrm{Y}$, Guo X-F, et al. Association between child and adolescent obesity and parental weight status: a cross-sectional study from rural North China. J Int Med Res 2013;41:1326-32.

55 Shafaghi K, Shariff ZM, Taib MNM, et al. Parental body mass index is associated with adolescent overweight and obesity in Mashhad, Iran Asia Pac J Clin Nutr 2014:23:225-31.

56 Maffeis C, Talamini G, Tatò L. Influence of diet, physical activity and parents' obesity on children's adiposity: a four-year longitudinal study. Int J Obes 1998;22:758-64.

57 Berge JM, Meyer CS, Loth K, et al. Parent/Adolescent weight status concordance and parent feeding practices. Pediatrics 2015;136:e591-8. 